\title{
INVESTIGACIÓN
}

Recibido: 12/03/2021 --- Aceptado: 15/04/2021 --- Publicado: 24/05/2021

\section{LA APLICACIÓN DEL NEUROMARKETING AL ÁMBITO DEL TURISMO: UNA REVISIÓN BIBLIOGRÁFICA}

\section{The application of neuromarketing to the field of tourism: a bibliographic review}

\author{
(1) (3) $\mathrm{R}^{\mathrm{T}}$ María Moral-Moral${ }^{1}$. Universidad de Cádiz. España. \\ maria.moral@uca.es
}

\section{Como citar el artículo:}

Moral-Moral, M. (2021). La aplicación del neuromarketing al ámbito del turismo: una revisión bibliográfica. Vivat Academia. Revista de Comunicación, 154, 429-442. http://doi.org/10.15178/va.2021.154.e1359

\section{RESUMEN}

El sector turístico es una actividad económica con un destacable peso en la economía mundial y nacional. La actual situación motivada por la pandemia del Covid-19 conducen a la necesidad de implementar técnicas y procedimientos que contribuyan a conocer las expectativas del turista y a mejorar la experiencia hacia el destino turístico con el objeto de incrementar su nivel de satisfacción. En este sentido, el desarrollo de las técnicas de neuromarketing aplicadas al sector turístico puede contribuir a mejorar la comprensión de los procesos emocionales y cognitivos de un turista y que deriven en un determinado comportamiento relacionado con la elección de un destino, nivel de satisfacción ante una experiencia turística, entre otros. Este artículo realiza una revisión de la literatura académica con el objeto de identificar la contribución del neuromarketing al campo del turismo. Para ello, se ha realizado una búsqueda bibliográfica en las principales bases de datos científicas (Wos, Scopus o Dialnet, entre otras). Los resultados muestran el estado actual del conocimiento en esta área y las futuras líneas de investigación a desarrollar. Cabe destacar, que la vinculación del neuromarketing con el turismo es aún incipiente. Se trata de un campo de investigación nuevo y con escasa atención entre los investigadores. En consecuencia, se recomienda el desarrollo de investigaciones empíricas más amplias que contribuyan a la implementación de técnicas de neuromarketing entre los responsables y gerentes turísticos.

\footnotetext{
${ }^{1}$ María Moral-Moral: Profesora Ayudante Doctor del Área de Comercialización e Investigación de Mercados de la Universidad de Cádiz. ORCID: 0000-0001-9078-8003.
} 


\author{
Moral-Moral, M. \\ La aplicación del neuromarketing al ámbito del turismo: una revisión bibliográfica
}

PALABRAS CLAVE: Neuromarketing - Neurociencia - Turismo - Revisión Bibliográfica - Bases de datos - Investigación - Destino turístico- COVID-19.

\begin{abstract}
The tourism sector is an economic activity with a remarkable weight in the world and national economy. Currently, the Covid-19 pandemic has led to the need to implement techniques and procedures that contribute to knowing the expectations of tourists and improving the experience of the tourist destination in order to increase their level of satisfaction. In this sense, the development of neuromarketing techniques applied to the tourism sector can contribute to improving the understanding of the emotional and cognitive processes of a tourist and that lead to a certain behavior related to the choice of a destination, level of satisfaction with a tourist experience, among others. This article conducts a review of the academic literature in order to identify the contribution of neuromarketing to the field of tourism. For this, a bibliographic search has been carried out in the main scientific databases (Wos, Scopus or Dialnet, among others). The results show the current state of knowledge in this area and the future lines of research to be developed. It should be noted that the link between neuromarketing and tourism is still incipient. It is a new field of research with little attention among researchers. Consequently, the development of broader empirical investigations that contribute to the implementation of neuromarketing techniques among tourism managers and managers is recommended.
\end{abstract}

KEYWORDS: Neuromarketing - Neuroscience - Tourism - Review - Bibliographic Databases - Research - Tourist destination - COVID-19.

\title{
1. INTRODUCCIÓN
}

El sector turístico es uno de los sectores de actividad con mayor relevancia para el desarrollo económico y social de los países de todo el mundo. Según la Organización Mundial de Turismo (O.M.T) en el año 2019, las llegadas de turistas internacionales, es decir aquellos que viajaron y pernoctaron por diferentes regiones del mundo alcanzó la cifra de 1.500 millones, lo que representa un incremento del $4 \%$ respecto al año anterior (O.M.T., 2020a).

En lo que se refiere a España, el sector turístico es uno de los principales pilares de la economía alcanzó la cifra de 154.487 millones de euros en 2019, lo que representa el $12,4 \%$ del PIB, y más concretamente el 12,9\% del empleo total del país con 2,72 millones de puestos de trabajo generados (INE, 2020).

No obstante, la reciente pandemia del COVID-19 ha ocasionado un impacto $y$ unas consecuencias sociales y económicas en el sector turístico nunca antes conocidas. Concretamente, el turismo internacional cayó un 72\% durante los primeros 10 meses del 2020, debido a las restricciones de movilidad impuestas para 
mitigar y controlar los efectos de la pandemia en la población mundial. En términos económicos, este impacto se traduce en una pérdida de 935.000 millones de dólares, lo que supone unas pérdidas diez veces superiores a las producidas por la crisis financiera de 2009 retrocediendo a niveles de hace treinta años (OMT, 2020b).

Ante esta situación, se hace imprescindible la adopción de medidas y estrategias turísticas innovadoras y creativas que permitan reducir los efectos negativos producidos por la pandemia, mejorando la experiencia turística y la competitividad de los destinos al ofrecer al turista una oferta ajustada a sus nuevas necesidades y demandas.

Es por ello, que la adopción de técnicas de neuromarketing en el ámbito turístico puede propiciar una mejora significativa de las experiencias ofrecidas, así como un mejor aprovechamiento de los recursos y competencias con los que cuentan los gestores turísticos.

Previamente, cabe aclarar que el concepto de neuromarketing es la combinación de neuro y marketing e implica la fusión de dos campos de estudio (neurociencia y marketing). El término no puede atribuirse a un autor en particular, ya que surgió espontáneamente en 2002. A partir de ese momento, diversas empresas estadounidenses de consultoría e investigación en neuromarketing empezaron a usar la tecnología y los conocimientos aportados por el área de la neurociencia (Morin, 2011). Si bien, la primera investigación académica fue realizada por Read Montague y publicada en 2004 .

En consecuencia, se denota que se trata de una disciplina de reciente estudio entre los académicos. A pesar de ello, es de destacar el importante número de investigaciones científicas realizadas sobre la misma ascendiendo a un total de 527 publicaciones indexadas en Web of Science, especialmente numerosas a partir del año 2015.

Así pues, el neuromarketing implica la aplicación de técnicas propias de la neurociencia al ámbito del marketing con el objeto de mejorar la comprensión e identificación de las respuestas de los consumidores ante los estímulos de marketing a través de la medición de la respuesta neuronal emitida por el cerebro. Su finalidad reside en mejorar la capacidad de los especialistas de marketing para diseñar e implementar estrategias más efectivas a través del conocimiento del comportamiento y de los procesos de toma de decisiones de las personas (Bakardjieva y Kimmel, 2017; Garzón-Paredes y Royo-Vela, 2021).

En esta línea, el neuromarketing puede suponer una destacable herramienta para el análisis y estudio de las decisiones, comportamientos y percepciones del consumidor turístico. Los procesos cognitivos en los cuales se basan nuestras decisiones tales como la elección de un destino turístico, alojamiento o bien, el impacto y efectividad generada por la publicidad turística, lo cual merece la atención de los investigadores con el objeto de dotar a los gerentes y a los entes decisores del 
sector turístico de información útil y significativa para mejorar las estrategias implementadas en el ámbito turístico.

En consecuencia, en este artículo se realiza una revisión de la literatura académica con el objeto de determinar el estado de la cuestión sobre el estudio del neuromarketing aplicado al campo del turismo. A priori, se podría esperar que el creciente número de investigaciones centradas en esta disciplina se traduzca en una proliferación de investigaciones aplicadas a diversos sectores de actividad, tales como el que nos ocupa, el turismo.

En definitiva, esta investigación se estructura de la siguiente forma. En primer lugar, la introducción en la que se destaca la importancia del sector analizado, las características del neuromarketing como disciplina, así como su vinculación y posible contribución al ámbito del sector turístico. En segundo lugar, se presentan los objetivos del trabajo, siguiendo con la inclusión de la metodología implementada para la consecución de los mismos. A continuación, se muestran los resultados alcanzados en la investigación, identificándose cuáles son las contribuciones científicas realizadas hasta el momento sobre el neuromarketing aplicado al ámbito del turismo. Finalmente, se extraen las principales conclusiones fruto de la investigación y análisis realizado. Asimismo, se presentan recomendaciones académicas y de gestión empresarial.

\section{OBJETIVOS}

El objetivo de este artículo radica en la realización de una revisión de la literatura académica con el objeto de identificar las aportaciones científicas realizadas a través del estudio y aplicación del neuromarketing al ámbito del turismo.

Se persigue determinar cuál es el estado de la cuestión sobre el desarrollo del neuromarketing en el sector turístico. La finalidad es conocer cuáles son las principales contribuciones, áreas de investigación y aplicaciones de esta disciplina.

Además, existe una inexistencia de investigaciones que realicen una revisión de la literatura sobre el ámbito en el que se centra el presente artículo. Por ello, se destaca el carácter novedoso de este trabajo y la necesidad de alcanzar los objetivos que se detallan con el objeto de identificar las áreas de investigación más importantes o bien, aquellas posibles lagunas de investigación que requieran una mayor atención por parte de los académicos.

A continuación, se procede a detallar la metodología adoptada para la consecución de los objetivos y fines de este trabajo.

\section{METODOLOGÍA}

La metodología implementada en esta investigación se basa en una revisión crítica sobre el tema objeto de estudio. Se adopta como metodología el método de Análisis 
de Contenido para examinar la terminología, el alcance y los campos de investigación analizados por los académicos.

En esta revisión de la literatura se sigue el procedimiento adoptado en otros trabajos, como Skavronskaya et al. (2017). Concretamente, se procedió a la búsqueda del término citado como "neuromarketing" + "tourism" o "destination" en dos repositorios científicos: Web os Science (Wos) y Scopus, debido al alcance multidisciplinar del campo de estudio analizado. No obstante, también se ha considerado otras bases de datos como Dialnet, ABI/Inform o Emerald Insight. Este procedimiento se utilizó en revisiones recientes sobre el estado del arte en turismo (Rahimi et al., 2017).

En primer lugar, la búsqueda en Scopus arrojó un total de 9 resultados (incluyendo los términos de búsqueda en título, resumen y palabras clave). Específicamente, 5 artículos, 2 capítulos de libros y 2 conferencias durante el período 2014-2021.

En segundo lugar, la búsqueda se realizó en Web of Science, donde se identificaron un total de 10 artículos publicados en el período 2014-2019, concretamente en 2014 (2), 2015 (1), 2017 (1), 2018 (2), 2019 (3) y 2020 (1).

En resumen, ambas bases de datos suman un total de 13 aportaciones durante el período 2014-2021 debido a que gran parte de dichas aportaciones aparecen incluidas tanto en Web of Science como Scopus. La mayoría de ellas publicadas en 2019 (3) y 2020 (2). Las restantes fueron realizadas en 2018 (2), 2017 (1), 2016 (1), 2015 (1) y 2014 (2). Finalmente, en 2021 hubo un resultado hasta el momento de cerrar esta búsqueda. Entre los investigadores destacan Hakan Boz y Erdogan Koc con 2 aportaciones cada uno.

También, se observa que no existe ningún centro o institución de investigación que destaque significativamente, aunque los países de origen más representados son España y Turquía. El artículo escrito por Koc y Boz (2014) destaca como el más citado al momento del cierre esta investigación, con 30 citas (en la base de datos Web of Science a 21 de enero de 2021).

Asimismo, en lo que se refiere a aquellas investigaciones indexadas en Dialnet. Los resultados arrojan un total de solo 3 contribuciones. No obstante, destacable es la única tesis doctoral realizada en España sobre el topic de esta investigación por Tinoco Egal (2020). Esta tesis valora mediante metodologías de neuromarketing la generación de empatía y confianza sobre diversos contenidos audiovisuales referidos a varias regiones turísticas de Ecuador. Por otro lado, en cuanto al resto de bases de datos analizadas los resultados obtenidos son residuales. Las escasas publicaciones encontradas se encuentran indexadas en las principales bases de datos analizadas Web of Science y Scopus.

Finalmente, es destacable el escaso número de resultados encontrados y la limitada presencia de investigaciones sobre neuromarketing en revistas científicas 
especializadas en el ámbito del turismo. Concretamente, solo dos aportaciones en las revistas: Tourism Management Perspectives y Tourism Management.

A continuación, se procede a mostrar los resultados de dicho análisis.

\section{RESULTADOS}

La revisión de la literatura realizada hasta la fecha de cierre de la investigación 21 de enero de 2021 arroja un total de 13 contribuciones científicas que relacionan el ámbito del neuromarketing con el turismo. Dichas investigaciones se presentan en la Tabla 1.

Así pues, procediendo a realizar el Análisis de Contenido de las contribuciones identificadas se encuentran las siguientes temáticas o topics de investigación.

Tabla 1. Investigaciones realizadas sobre la aplicación del neuromarketing al ámbito del turismo.

\begin{tabular}{|c|c|c|c|c|c|}
\hline $\mathrm{N}^{\mathrm{o}}$ & Investigación & Temática & Fuente & Scopus & WOS \\
\hline 1 & $\begin{array}{l}\text { Garzón-Paredes y } \\
\text { Royo-Vela (2021) }\end{array}$ & Imagen destino & Capítulo libro & $X$ & \\
\hline 2 & Hsu y Chen (2020) & $\begin{array}{ll}\text { Elección } & \text { vino. } \\
\text { Enoturismo } & \end{array}$ & $\begin{array}{ll}\text { British } & \text { Food } \\
\text { Journal } & \end{array}$ & & $X$ \\
\hline 3 & Ladkoo (2020) & $\begin{array}{l}\text { Promoción festivales } \\
\text { y eventos turísticos }\end{array}$ & Capítulo libro & $X$ & \\
\hline 4 & $\begin{array}{ll}\text { Ionescu } & y \\
\text { Romanelli (2019) }\end{array}$ & $\begin{array}{ll}\text { Diseño } & \text { webs } \\
\text { turísticas } & \end{array}$ & Proceedings Paper & & $X$ \\
\hline 5 & Michael et al. (2019) & $\begin{array}{l}\text { Imagen destino } \\
\text { Elección destino } \\
\text { turístico }\end{array}$ & $\begin{array}{l}\text { Journal of Islamic } \\
\text { Marketing }\end{array}$ & $x$ & $x$ \\
\hline 6 & $\begin{array}{l}\text { Muñoz-Leiva et al. } \\
\text { (2019) }\end{array}$ & $\begin{array}{l}\text { Publicidad en web, } \\
\text { blogs y redes sociales }\end{array}$ & $\begin{array}{ll}\text { Physiology } & \& \\
\text { Behavior } & \end{array}$ & $x$ & $x$ \\
\hline 7 & $\begin{array}{l}\text { Bastiaansen et al. } \\
(2018)\end{array}$ & Imagen destino & $\begin{array}{ll}\text { Journal } & \text { of } \\
\text { destination } & \\
\text { marketing } & \& \\
\text { management } & \end{array}$ & $X$ & $X$ \\
\hline 8 & $\begin{array}{l}\text { Barrera Ortegon y } \\
\text { Sarmiento (2018) }\end{array}$ & Conceptual & Capítulo libro & & $X$ \\
\hline 9 & Boz et al. (2017) & Percepción precios & $\begin{array}{l}\text { Tourism } \\
\text { Management } \\
\text { Perspectives }\end{array}$ & $X$ & $X$ \\
\hline 10 & $\begin{array}{l}\text { Chavaglia et al. } \\
\text { (2016) }\end{array}$ & Conceptual & Capítulo de libro & $X$ & \\
\hline 11 & Seric et al. (2015) & $\begin{array}{l}\text { Posicionamiento } \\
\text { destino }\end{array}$ & Proceedings Paper & & $X$ \\
\hline 12 & Koc y Boz (2014) & Conceptual & $\begin{array}{l}\text { Tourism } \\
\text { Management }\end{array}$ & $X$ & $X$ \\
\hline 13 & Ma et al. (2014) & Conceptual & Proceedings Paper & $X$ & $X$ \\
\hline
\end{tabular}

Fuente: elaboración propia. 
En primer lugar, cabe destacar que uno de los principales temas de investigación es el determinar cómo la imagen de un destino turístico puede influir en las preferencias de viaje de un individuo.

Por ello, una de las investigaciones más recientes hasta la fecha sobre dicha temática es la realizada por Garzón-Paredes y Royo-Vela (2021). Estos investigadores determinan que la imagen del destino está constituida por una serie de pensamientos, opiniones, sentimientos e intenciones determinada por una serie elementos cognitivos, afectivos y conativos, que forman este constructo y que influyen en el proceso de decisión del turista. De modo que estos componentes cognitivos y emocionales son evaluados a través de la presentación de vídeos de realidad virtual sobre del patrimonio cultural y arquitectónico del destino, en este caso de España. Para ello, se emplean como técnicas de registro de las ondas cerebrales del individuo, el electroencefalograma. Los hallazgos muestran que el impacto emocional y cognitivo del patrimonio emulado con realidad virtual influye positivamente en la imagen del destino virtual y reafirma los efectos emocionales y cognitivos positivos del patrimonio.

Por su parte, Michael et al. (2019) centran su atención en profundizar en el estudio de la imagen de un destino turístico. Identificaron que existen diferencias emocionales y cognitivas generales entre los canales a través de los cuales los destinos turísticos son presentados. Las palabras y los nombres de los destinos provocan una mayor carga cognitiva, debido a la mayor carga asociativa que tienen las palabras frente a las imágenes. De este modo, aprecian que las imágenes y los vídeos proporcionan una respuesta emocional más alta. Resaltan que las emociones juegan un papel muy relevante en la atención, percepción, memoria y comportamiento final de un individuo. Concluyen que las decisiones sobre el destino turístico tienen un componente inconsciente y un componente directo que puede impulsar o afectar a la preferencia manifestada por el individuo y su elección final.

Finalmente, coinciden en señalar la escasez de investigaciones que aborden desde el ámbito del neuromarketing el estudio de los destinos turísticos y su imagen a través del análisis de palabras, vídeos o imágenes. Además, consideran que la investigación en turismo puede ser un campo propicio para comprender la mente de un individuo durante el proceso de formación y elección de decisiones más complejas proponiendo un nuevo término o área de investigación denominada "neuroturismo".

No obstante, el primer trabajo que propuso el término de "neuroturismo" es el realizado por Ma et al. (2014). Dichos autores recomiendan la aplicación de la neurociencia a las ciencias sociales. Más concretamente, al contexto del turismo explorando los comportamientos de los turistas capturando aspectos cognitivos y emocionales del turista durante el desarrollo de una experiencia turística. Esta información permitiría al gerente turístico un mejor diseño y seguimiento de los productos o servicios turísticos que ofrece al turista. 
A pesar de todo ello, son escasos los trabajos que utilizan el término de "neuroturismo" siendo un concepto desconocido. Si bien, podría utilizarse como área para delimitar la aplicación y estudio del neuromarketing en la disciplina turística.

Otro relevante trabajo es el realizado por Bastiaansen et al. (2018) en el que analizan la respuesta emocional de los individuos ante la visualización de un vídeo sobre un destino turístico. Aprecian una alta respuesta emocional al estímulo recibido. No obstante, advierten de que esta respuesta emocional fue medida unos minutos después de que los individuos fueran expuestos al estímulo, por lo que sugieren verificar la consistencia de dicha respuesta. Además, destacan que las emociones son predictores de la conducta de compra. Sin embargo, el estudio no pudo probar el comportamiento de compra ni la intención de visita de los participantes.

Por otro lado, otras investigaciones como la realizada por Hsu y Chen (2020) persiguen evaluar el efecto de la música en la selección de productos, como el vino. Consideran que las preferencias de cata de vino de un individuo estarían condicionadas por los diferentes géneros de estímulos musicales. En consecuencia, evidencian la existencia de asociaciones significativas entre el género del estímulo musical y la elección realizada por el individuo. En este sentido, proporcionan una evidencia empírica sobre cómo usar la música de manera efectiva en estrategias de marketing, más concretamente en la promoción de modalidades turísticas como podría ser el enoturismo.

En lo que se refiere al estudio de ámbitos más específicos relacionados con el turismo Ladkoo (2020) propone que el neuromarketing puede ayudar a evaluar la visualización y promoción de innovaciones sostenibles y verdes en los principales festivales y eventos turísticos. El autor considera que el neuromarketing puede identificar las emociones que determinan que una persona visite determinados eventos turísticos, como es el caso de los festivales.

Así mismo, otra área interesante de investigación es comprender el comportamiento del consumidor turístico durante el proceso de búsqueda de información en un sitio web.

En este sentido, Ionescu y Romanelli (2019) analizan el diseño de diversas webs turísticas utilizando como técnica el Eye Tracking. Ponen de manifiesto errores en la ubicación de la información en el sitio web, de la usabilidad de los mismos. Además, determinan cómo los usuarios navegan por el sitio web, identificando qué tipos de imágenes y contenido son preferidos por los turistas. Este análisis contribuye a ofrecer instrucciones para rediseñar el sitio web, recomendando la participación del sujeto en el diseño web, lo que permitirá incrementos en las ventas de la página web.

Otro tipo de investigaciones son las relacionadas con la publicidad presentada en sitios webs, blogs o redes sociales. 


\section{Moral-Moral, M. \\ La aplicación del neuromarketing al ámbito del turismo: una revisión bibliográfica}

Así pues, destaca el trabajo realizado por Muñoz-Leiva et al. (2019) donde evalúan la atención visual y memoria autoinformada o de recuerdo. Las mediciones fueron realizadas a través del seguimiento ocular de los participantes en el estudio recibiendo instrucciones para visitar tres sitios webs de un hotel (blog, perfil en Facebook y perfil en la comunidad virtual de Tripadvisor). Los resultados revelaron una mayor efectividad publicitaria en el caso de la red social hotelera (Facebook). Las medidas de atención visual basadas en los datos de seguimiento ocular diferían de las medidas de recuerdo autoinformado. Concretamente, la atención visual al banner publicitario ofreció un bajo nivel de conciencia. Recomiendan que los anunciantes realicen un estudio previo del sitio web en el que quieran mostrar sus anuncios, así como del tipo de tarea que los usuarios realicen más en ese sitio web (por ejemplo, compra de un producto determinado, información de búsqueda, etc.). De esta forma, tanto el diseño como el contenido del banner estará orientado al objetivo del usuario, evitando así su molestia, mejorando las tasas de atención y de recuerdo. Así mismo, sugieren incluir celebridades en la imagen del banner, más concretamente personajes que estén relacionados con el contenido mostrado. Esto contribuirá a un mejor reconocimiento y recuerdo de la información.

Por otro lado, Barrera Ortegon y Sarmiento (2018) realizan una breve revisión conceptual de la vinculación del neuromarketing con el turismo. Sugieren identificar las emociones del turista con el objeto de mejorar el posicionamiento del destino y la efectividad de las experiencias y servicios ofrecidos al visitante.

En esta línea, se sitúa el trabajo de Chavaglia et al. (2016) en el que realizan una visión introductoria del neuromarketing en el ámbito del turismo. Destacan las ventajas de la aplicación de las técnicas de neuromarketing en la compresión de los motivos y emociones que guían a los turistas.

Otro tema de investigación es el abordado por Boz et al. (2017). Investigan sobre las influencias psicológicas del precio de un producto o servicio turístico en el cliente. Consideran que, debido a la falta de elementos tangibles en los servicios turísticos, los clientes pueden atribuir un mayor significado al precio. Así pues, realizan una revisión de las diversas herramientas o métodos de neuromarketing y destacan, que gracias a estos se puede obtener información más completa sobre la comprensión de los precios desde el punto de vista de los clientes, aumentando la validez y confiabilidad en la percepción de los precios por parte de los consumidores.

Seric et al. (2015) evalúan en su trabajo la utilidad del neuromarketing para posicionar un destino turístico. Así pues, confirman la aplicabilidad de las técnicas de neuromarketing para determinar las pautas de posicionamiento de una marca destino. Afirman que el foco para el posicionamiento del destino, debe estar en el acto de lograr la diferenciación del simbolismo del contenido, y de la oferta turística específica que el destino representa. Determinan que, aunque el cerebro de cada persona es único, la reacción a los estímulos es bastante similar, por lo que los resultados obtenidos con las técnicas de neuromarketing pueden servir para

Vivat Academia. Revista de Comunicación. 2021, nº 154, 429-442 
anticipar diversas reacciones de los turistas a determinados estímulos. Concluyen que las técnicas de neuromarketing podrían generar conocimientos innovadores, valiosos y útiles en cuanto a la gestión de la marca destino por lo que recomiendan la realización de investigaciones en esta línea.

Finalmente, cabe resaltar que uno de los primeros trabajos sobre el estudio del neuromarketing en el contexto turístico es el realizado por Koc y Boz (2014). Se trata de uno de los trabajos más citados con 30 citas. Esta aportación es un intento de explorar y relacionar algunos de los estudios potencialmente relevantes en psicología, neurología, biología y química con el marketing turístico. Sugieren un enfoque único para el estudio del comportamiento de los consumidores turísticos denominado "psiconeurobioquímica". Así mismo, consideran necesario profundizar en torno a la investigación sobre esta disciplina debido a que permitirá a los gerentes turísticos un mejor diseño de sus ofertas turísticas aumentando la satisfacción y la lealtad de sus clientes.

Una vez expuestos los resultados de esta revisión bibliográfica sobre las investigaciones científicas realizadas sobre la aplicación y estudio del neuromarketing en el contexto turístico. Se procede a continuación, a comentar las conclusiones obtenidas en la realización del presente trabajo.

\section{CONCLUSIONES}

En la actualidad, la aplicación de diversas técnicas de neuromarketing contribuye a mejorar el conocimiento sobre los procesos de toma de decisiones de los individuos y en particular, de los consumidores. Permite evaluar la efectividad de los estímulos recibidos para propiciar una determinada respuesta cognitiva, emocional o conativa en el sujeto. De ahí, que el estudio de esta joven disciplina científica haya suscitado el interés entre los investigadores y la proliferación de numerosas investigaciones en diversos campos.

En este trabajo se ha procedido a determinar el estado de la cuestión sobre el estudio del neuromarketing en el sector turístico a través de la revisión de la literatura académica en las principales bases de datos científicas (Web of Science o Scopus, entre otras).

La elección del sector turístico no resulta casual. Se trata de uno de los sectores económicos con mayor peso en la economía española generador de riqueza y empleo. No obstante, la pandemia del Covid-19 ha puesto en serio peligro la supervivencia de numerosas empresas pertenecientes a diferentes subsectores turísticos (hotelero, restauración, aerolíneas, agencias de viaje, etc.,). Por ello, se hace cada vez más necesario la adopción de estrategias y procedimientos innovadores que permitan una regeneración del sector, y de los productos y servicios turísticos ofrecidos.

En este sentido, los resultados obtenidos han puesto de manifiesto que la aplicación de las técnicas de neuromarketing en el sector turístico contribuye a un 
mejor diseño de los mensajes, estímulos o informaciones presentadas al turista o visitante. Especialmente importante es cuidar la organización y los estímulos presentados en páginas webs, redes sociales, etc., dado el importante uso que el turista realiza de las mismas en la búsqueda de información sobre un destino, o bien como canal para la toma de decisiones y compra efectiva de un producto o servicio turístico.

A pesar de ello, cabe resaltar el reducido número de trabajos científicos sobre el tema abordado en el presente trabajo. Solo se encontraron 13 contribuciones científicas publicadas durante el período 2014-2021. Destacan aquellas investigaciones dirigidas a determinar cómo se constituye la imagen de un destino turístico en un individuo, y cómo esta puede influir en las preferencias de viaje de un individuo. Y por otro lado, aquellos trabajos dirigidos a comprender el comportamiento del consumidor turístico durante el proceso de búsqueda de información en sitios webs, así como las dirigidas a determinar el grado de efectividad de la publicidad presentada en sitios webs, blogs o redes sociales turísticas.

Actualmente, el estudio del neuromarketing en el sector turístico ha sido escasamente analizado y estudiado. Las futuras líneas de investigación son amplias y diversas dadas las escasas investigaciones realizadas hasta el momento (ej. impacto publicidad online, satisfacción producto/servicio turístico, percepción de un destino turístico, etc.,). Por ello, se recomienda a los investigadores un mayor esfuerzo de investigación en el campo turístico debido a las particularidades que presenta este sector económico. Además, se hace imprescindible para propiciar una mayor aplicación y difusión de las técnicas de neuromarketing por parte de los gerentes turísticos en el diseño de sus estrategias comerciales.

En definitiva, el neuromarketing puede contribuir a una efectiva recuperación y reinvención del sector turístico tras la pandemia gracias a la implementación de estrategias que propicien el desarrollo de mejores productos y servicios turísticos más ajustados a las necesidades actuales del turista gracias al conocimiento que otorga la aplicación de dichas técnicas.

\section{REFERENCIAS}

Bastiaansen, M., Straatman, S., Driessen, E., Mitas, O., Stekelenburg, J. y Wang, L (2018). My destination in your brain: A novel neuromarketing approach for evaluating the effectiveness of destination marketing. Journal of Destination $\begin{array}{lllll}\text { Marketing } \mathcal{E} & \text { Management, } & 7, & 76-88 .\end{array}$ https://www.doi.org/10.1016/j.jdmm.2016.09.003

Bakardjieva, E. y Kimmel, A. J. (2017). Neuromarketing Research Practices: Attitudes, Ethics, and Behavioral Intentions. Ethics \& Behavior, 27(3), 179-200. https://www.doi.org/10.1080/10508422.2016.1162719. 
Barrera Ortegon, A. P. y Sarmiento, N. (2018). Neuromarketing and tourism an opportunity to grow. En libro: Perspectivas y desafíos para la competitividad: una mirada global desde los territorios (S.R.M. Arevalo., M. A. Avendano y J. A. P. Martínez, eds), pp. 161-177.

Boz, H., Arslan, A. y Koc, E. (2017). Neuromarketing aspect of tourısm pricing psychology. Tourism Management Perspectives 23, 119-128. https://www.doi.org/10.1016/j.tmp.2017.06.002

Chavaglia, J., Filipe, J. A. y Ferreira, M. A. M. (2016). Neuromarketing applied to tourism: An introductory vision. En libro: Modeling and New Trends in Tourism: A Contribution to Social and Economic Development (K. Rontos y J. A. Filipe eds), pp 135-150.

Garzón-Paredes, A. R. y Royo-Vela, M. (2021). Experimenting Through Neuromarketing to Measure the Impact of Spanish Cultural Heritage. En libro: Advances in Tourism, Technology and Systems. Selected Papers from ICOTTS20, Volume 2 (A. Abreu., D. Liberato., E. Alén González y J.C. García Ojeda, eds). Springer.

Instituto Nacional de Estadística (I.N.E). (2020). Cuenta Satélite del Turismo en España, año 2019. https:// www.ine.es/dyngs/INEbase/es/operacion.htm?c=Estadistica_C\&cid=12 $\underline{54736169169 \& m e n u=u l t i D a t o s \& i d p=12547355768633}$

Ionescu, A. M. y Romanelli, M. (2019). Rediscovering Neuromarketing for Sustainable Companies. En libro: Strategica: upscaling digital transformation in business and economics. 7th International Academic Conference on Strategica Upscaling Digital Transformation in Business and Economics. Bucharest, Romania, Oct 10-11, 2019.

Hsu, L. W. y Chen, Y. J. (2020). Music and wine tasting: an experimental neuromarketing study. British food journal. 122(8), 2725-2737. https://www.doi.org/10.1108/BFJ-06-2019-0434

Koc, E. y Boz, H. (2014). Psychoneurobiochemistry of tourism marketing. Tourism management, 44, 140-148. https:// www.doi.org/10.1016/j.tourman.2014.03.002

Ladkoo, A. D. (2020). Neuromarketing and greenovation in festival and event tourism: The case of a small island developing state-Mauritius. En libro: Festival and Event Tourism Impacts, (D. Gursoy., R. Nunkoo y M. Yolal, eds), pp. 221-233.

Ma, Q. G., Hu, LF., Pei, G. X., Ren, P. Y. y Ge, P. (2014). Applying Neuroscience to Tourism Management: A Primary Exploration of Neurotourism. En libro: Applied mechanics, materials and manufacturing IV (Liu, H., Kuroda, S. I. y Zheng, L., 
La aplicación del neuromarketing al ámbito del turismo: una revisión bibliográfica

$\begin{array}{llll}\text { eds). } & \text { Vol 670-671, } & \text { 1637-1640. }\end{array}$ https://www.doi.org/10.4028/www.scientific.net/AMM.670-671.1637

Michael, I., Ramsoy, T., Stephens, M. y Kotsi, F. (2019). A study of unconscious emotional and cognitive responses to tourism images using a neuroscience method. Journal of Islamic Marketing, $10 \quad$ (2), 543-564. https://www.doi.org/10.1108/JIMA-09-2017-0098

Morin, C. (2011). Neuromarketing: The New Science of Consumer Behavior. Society, 48, 131-135. https://www.doi.org/10.1007/s12115-010-9408-1

Muñoz-Leiva, F., Hernández-Méndez, J. y Gómez-Carmona, D. (2019). Measuring advertising effectiveness in Travel 2.0 websites through eyetracking technology. $\begin{array}{lllll}\text { Physiology } & \mathcal{E} & \text { Behavior } & \text { 83-95. }\end{array}$ https://www.doi.org/10.1016/j.physbeh.2018.03.002

Organización Mundial de Turismo (O.M.T) (2020a). UNWTO World Tourism Barometer. Vol 18. January 2020. https://www.unwto.org/world-tourismbarometer-n18-january-2020

Organización Mundial de Turismo (O.M.T) (2020b). El turismo retrocede a niveles de 1990 con una caída en llegadas del más del $70 \%$. https://www.unwto.org/es/taxonomy/term/347

Rahimi, R., Ko“seoglu, M. A., Ersoy, A. B. y Okumus, F. (2017). Customer relationship management research in tourism and hospitality: a state of the art. Tourism Review, 72 (2), 209-220. https://www.doi.org/10.1108/TR-01-2017-0011

Seric, N., Jurisic, M. y Petricevic, D. (2015). Neuromarketing potential for tourist destination brand positioning. 3rd International Scientific Conference onTourism in Southern and Eastern Europe (ToSEE 2015) Opatija, Croatia. Colección: Tourism in South East Europe, Vol 3, 429-439.

Skavronskaya, L., Scott, N., Moyle, B., Le, D., Hadinejad, A., Zhang, R., Gardiner, S., Coghlan, A. y Shakeela, A. (2017). Cognitive psychology and tourism research: state of the art. Tourism Review, 72 (2), 221-237. https://www.doi.org/10.1108/TR-03-2017-0041

Tinoco Egas, R. (2020). Aplicaciones de neuromarketing para generar confianza: Análisis del turismo en Ecuador. Tesis Doctoral. Universidad de La Coruña, España. 


\section{AUTORA:}

\section{María Moral-Moral}

Profesora Ayudante Doctor del Área de Comercialización e Investigación de Mercados de la Universidad de Cádiz. Doctora en Ciencias Sociales y Jurídicas por la Universidad de Cádiz. Licenciada en Administración y Dirección de Empresas por la Universidad de Jaén. Profesora en el Grado de Administración y Dirección de Empresas, Grado de Marketing e Investigación de Mercados, Máster en Dirección Turística, Máster en MBA y coordinadora del Módulo de Marketing emprendedor en el Máster de Creación de Empresas, Nuevos Negocios y Proyectos Innovadores (Masterup). Líneas de investigación centradas en el marketing turístico, nuevas modalidades turísticas e innovación docente.

Orcid ID: https://orcid.org/orcid-search/search?searchQuery=0000-0001-9078-8003

Google Scholar: https:/ / scholar.google.es/ citations?user=81eQGZgAAAAJ\&hl=es

ResearchGate: https://www.researchgate.net/profile/Maria_Moral-Moral

Scopus ID: 57202045219

Researcher ID: H-3818-2013

Dialnet: $\underline{\text { https:/ / dialnet.unirioja.es/servlet/autor?codigo=2992688 }}$ 